\title{
Impactos psicológicos da pandemia do SARS-CoV-2 na população mundial: Uma
}

\section{revisão integrativa}

\author{
Psychological impacts of the SARS-CoV-2 Pandemic on the World Population: An Integrative \\ Review
}

Impactos psicológicos de la pandemia del SARS-CoV-2 en la población mundial: Una revisión

integrador

Recebido: 19/05/2021 | Revisado: 24/05/2021 | Aceito: 25/05/2021 | Publicado: 25/05/2021

\author{
Maria Rosemary Da Silva Gomes \\ ORCID: https://orcid.org/0000-0002-8217-3647 \\ Centro Universitário Santo Agostinho, Brasil \\ E-mail: mariarosemary2010@gmail.com \\ Lana Almeida Silva \\ ORCID: https://orcid.org/0000-0002-5431-1694 \\ Centro Universitário Santo Agostinho, Brasil \\ E-mail: almeidalana18@gmail.com \\ Liana Dantas da Costa e Silva Barbosa \\ ORCID: https://orcid.org/0000-0002-8191-102X \\ Centro Universitário Santo Agostinho, Brasil \\ E-mail: dantasliana@bol.com.br
}

\begin{abstract}
Resumo
O SARS-CoV-2 causador da atual pandemia de COVID-19, apresenta-se como um problema para a saúde pública, na qual além das preocupações quanto à saúde física, traz também preocupações quanto ao sofrimento psicológico. O objetivo do estudo foi analisar as evidências científicas acerca dos impactos psicológicos e outras alterações na saúde mental da população brasileira na Pandemia do SARS-CoV-2, identificando os principais fatores que levam à população mundial a desencadear problemas de saúde mental e apresentar estratégias de prevenção e enfrentamento dos impactos psicológicos sofridos pela população mundial na pandemia. O presente estudo trata-se de uma revisão integrativa, na qual a amostra de com 27 artigos foi composta a partir de um levantamento de dados através da busca na Biblioteca Virtual em Saúde (BVS) onde estão indexadas as bases de dados eletrônicas utilizadas na pesquisa: SCIELO (Scientific Eletronic Library Online), LILACS (Literatura Latino-Americana e do Caribe em Ciências da Saúde), BDENF (Base de Dados da Enfermagem), PubMed (NCBI) e Google Acadêmico, nos anos de 2020 a 2021. Os descritores foram cruzados entre si utilizando o marcador e booleano AND. A coleta foi realizada no período de Agosto a Novembro de 2020. A importância da implementação de estratégias e ou intervenções para que a população tenha acesso à medidas de apoio emocional diante a pandemia do SARS-CoV-2, seja presencial ou online. Levando em consideração as diferentes populações afetadas, recomenda-se lidar com as consequências na saúde mental diante da pandemia e intervenções psicológicas em resposta às necessidades individuais no decorrer do surto pandêmico.
\end{abstract}

Palavras-chave: Infecções por Coronavírus; Pandemias; Saúde mental; Brasil; Enfermagem.

\begin{abstract}
SARS-CoV-2, the cause of the current COVID-19 pandemic, presents itself as a problem for public health, in which, in addition to concerns about physical health, it also brings concerns about psychological suffering. The objective of this study was to analyze the scientific evidence about the psychological impacts and other alterations in the mental health of the Brazilian population in the SARS-CoV-2 Pandemic, identifying the main factors that lead the world population to unleash mental health problems and present strategies for preventing and coping with the psychological impacts suffered by the world population in the pandemic. This study is an integrative review, in which the sample of 27 articles was composed from a survey of data through a search in the Virtual Health Library (VHL) where the electronic databases used in the research are indexed: SCIELO (Scientific Eletronic Library Online), LILACS (Latin American and Caribbean Literature on Health Sciences), BDENF (Nursing Database), PubMed (NCBI) and Google Academic, in the years 2020 to 2021. The descriptors were crossed with each other using the Boolean AND marker. The collection was carried out from August to November 2020. The importance of implementing strategies and/or interventions so that the population has access to emotional support measures in the face of the SARS-CoV-2 pandemic, whether in person or online. Taking into consideration the different populations affected, it is recommended to address
\end{abstract}


the mental health consequences of the pandemic and psychological interventions in response to individual needs during the course of the pandemic outbreak.

Keywords: Coronavirus infections; Pandemics; Mental health; Brazil; Nursing.

\section{Resumen}

El SARS-CoV-2, causante de la actual pandemia de COVID-19, se presenta como un problema para la salud pública, en el que además de la preocupación por la salud física, también conlleva la preocupación por el sufrimiento psicológico. El objetivo del estudio fue analizar las evidencias científicas sobre los impactos psicológicos y otros cambios en la salud mental de la población brasileña en la pandemia de SARS-CoV-2, identificando los principales factores que llevan a la población mundial a desencadenar problemas de salud mental y presentar estrategias de prevención y afrontamiento de los impactos psicológicos sufridos por la población mundial en la pandemia. Este estudio es una revisión integradora, en la cual la muestra de 27 artículos fue compuesta a partir de un levantamiento de datos a través de una búsqueda en la Biblioteca Virtual de Salud (BVS) donde están indexadas las bases de datos electrónicas utilizadas en la investigación: SCIELO (Scientific Electronic Library Online), LILACS (Latin American and Caribbean Literature on Health Sciences), BDENF (Nursing Database), PubMed (NCBI) y Google Academic, en los años 2020 a 2021. Los descriptores se cruzaron entre sí utilizando el marcador booleano AND. La recogida se realizó en el periodo comprendido entre agosto y noviembre de 2020. La importancia de implementar estrategias y/o intervenciones para que la población tenga acceso a medidas de apoyo emocional ante la pandemia de SARS-CoV-2, ya sea en persona o en línea. Teniendo en cuenta las diferentes poblaciones afectadas, se recomienda abordar las consecuencias de la pandemia para la salud mental y las intervenciones psicológicas en respuesta a las necesidades individuales durante el brote pandémico.

Palabras clave: Infecciones por coronavirus; Pandemias; Salud mental; Brasil; Enfermería.

\section{Introdução}

De acordo com a constituição da Organização Mundial de Saúde (OMS), saúde é um estado de completo bem-estar físico, mental e social e não apenas a mera ausência de doença ou enfermidade (Brasil, 2020). E segundo a Fundação Osvaldo Cruz (FIOCRUZ), os impactos dos transtornos mentais associados ao SARS-CoV-2 (Síndrome Respiratória Aguda Grave de Coronavírus 2) mostra a importância notória de estudos que tragam mudanças na atenção psiquiátrica, assim como cuidados efetivos diante da atual situação pandêmica (Fiocruz, 2020).

A COVID-19 (doença do novo coronavírus 2019) é uma doença causada pelo vírus denominado SARS-CoV-2, que apresenta um espectro clínico variando de infecções assintomáticas a quadros graves (Brasil, 2020a). Com esse novo cenário, a implementação de medidas de contenção do vírus traz efeitos psicológicos negativos onde estudiosos têm debatido sobre as estratégias que ajudem no enfrentamento desses efeitos para tornar o período de quarentena menos adoecedor (Wang et al., 2020). É bastante visto que a pandemia trouxe um pânico global na saúde mental das pessoas que tinham suas vidas agitadas dadas as características da contemporaneidade, acarretando assim medo e aflição em contrair a doença e excesso de informações (Bagchi, 2020).

Estudos realizados por Wang et al. (2020) e Zhang et al. (2020) relataram que devido à distância da família e das relações sociais e ao risco de contaminação do SARS CoV-2, não apenas os pacientes e profissionais da saúde, mas toda a população (idosos, moradores de casa de repouso, mulheres e outros) é afetada mentalmente. Diante disso, estudos sugerem que junto à disseminação de informações falsas, as preocupações com a escassez de suprimentos, as perdas financeiras e o medo de ser infectado por um vírus potencialmente fatal, de rápida disseminação, cujas origens e natureza ainda são pouco conhecidos, acabam por afetar o bem-estar psicológico de muitas pessoas (Asmundson \& Taylor, 2020).

Devido à alta transmissibilidade do SARS-CoV-2, em março de 2020, foi declarado pela (OMS, 2020) estado de pandemia. De acordo com Wang et al., (2020) as medidas de contenção (MC) do vírus causam impactos psicológicos diretamente relacionados à COVID-19, onde essas medidas e a falta de preparação para prestar assistência em saúde mental durante o período pandêmico consistem em fatores de risco à saúde mental. Em pesquisas realizadas na população sobre a quarentena e o 
Research, Society and Development, v. 10, n. 6, e50010616286, 2021

(CC BY 4.0) | ISSN 2525-3409 | DOI: http://dx.doi.org/10.33448/rsd-v10i6.16286

isolamento social, Brooks et al. (2020) identificaram os efeitos negativos dessas medidas que incluem sintomas de estresse póstraumático, confusão, raiva e medo, podendo se tornar crônico ou desproporcional.

Santana, Nascimento, Lima e Nunes (2020) constatam que o isolamento social na pandemia do SARS-CoV-2 levou as pessoas a serem acometidas por mudanças psicológicas, como ansiedade, depressão e estresse, devido ao ser humano ser um ser social e por isso, dependem de interação, interação interpessoal, e quando mantidas em isolamento, alimentam sentimentos de solidão e tristeza. É de suma importância a implementação de estratégias e ou intervenções para que a população tenha acesso a medidas de apoio emocional diante desta pandemia do SARS-CoV-2, seja presencial ou online (Brasil, 2020b). Estudos acerca do SARS-CoV-2 e o enfrentamento dos problemas mentais desencadeados devido às medidas de contenção deste, têm evidenciado que o processo de revisão de literatura é relevante, pois oferece benefícios para a elaboração de ações e políticas públicas direcionadas à coletividade e as equipes de saúde. Assim, o objetivo deste estudo é analisar as evidências científicas acerca dos impactos psicológicos na saúde mental nas populações durante a Pandemia do SARS-CoV-2.

\section{Metodologia}

O presente estudo foi desenvolvido através de uma pesquisa de revisão integrativa, método que permite criticar e sintetizar o conhecimento produzido de forma ordenada e sistemática, com a finalidade de gerar um todo consistente e significativo por meio de achados oriundos de estudos diversos e representativos sobre determinado tema. Faz uso de publicações com características metodológicas diferentes, contudo sem ir de encontro ao perfil epistemológico dos estudos empíricos pesquisados, contribuindo para o avanço da ciência à medida que permite o levantamento de lacunas a serem preenchidas para o aprofundamento do tema (Soares et al., 2014).

Trata-se de uma pesquisa bibliográfica de revisão integrativa, na qual classifica-se como pesquisa básica estratégica, estruturando-se em seis etapas distintas: 1) trata-se da elaboração da questão de pesquisa; 2) amostragem ou busca na literatura dos estudos primários; 3) extração de dados dos estudos primários; 4) avaliação dos estudos primários incluídos na revisão; 5) análise e síntese dos resultados da revisão; 6) apresentação da revisão integrativa (Mendes, Silveira, Galvão, 2008). A questão norteadora que fundamentou a sua construção foi: Quais as evidências científicas acerca dos impactos psicológicos da pandemia do SARS-CoV-2 enfrentados pela população brasileira?

Para a amostra foi realizado, no período de agosto a novembro de 2020, um levantamento de textos por meio de busca na Biblioteca Virtual em Saúde (BVS) onde estão indexadas as bases de dados eletrônicas utilizadas nesta pesquisa: SCIELO (Scientific Eletronic Library Online), LILACS (Literatura Latino-Americana e do Caribe em Ciências da Saúde), BDENF (Base de Dados da Enfermagem), PubMed (NCBI) e Google Acadêmico, nos anos de 2020 a 2021. Foram utilizados os descritores contidos no site dos Descritores em Ciências da Saúde (DeCS) e do Medical Subject Headings (MeSH) sendo estes: Infecções por Coronavírus (Coronavírus Infections), Pandemias (Pandemics), Saúde mental (Mental Health), Brasil (Brazil), Enfermagem (Nursing). Esses descritores foram cruzados entre si utilizando o marcador booleano AND.

Após os cruzamentos iniciais mencionados, foram adotados como critérios de inclusão: estudos de revisão, artigos na íntegra online, publicados no período dos últimos cinco anos de 2020 e 2021, nos idiomas Português, Inglês e Espanhol, que seguem os descritores acima, onde os estudos incluídos precisavam abordar os impactos psicológicos e outras alterações da pandemia do SARS-CoV-2 na população mundial. Tem como foco do estudo profissionais da saúde, idosos, moradores de casa de repouso, crianças, adultos e pacientes com problemas mentais preexistentes. Em seguida foram aplicados os critérios de exclusão: dissertações, teses, editoriais, cartas ao editor, relatos de experiência, resumos de eventos e os repetidos (duplicados); artigos que não são completos e que não estejam relacionados à temática do estudo. 
Trata-se de uma revisão integrativa, na qual a seleção das publicações para a revisão seguiu as orientações da estratégia de busca PICO (Quadro 1), onde a questão de pesquisa estabelecida conta com 4 componentes: P (Paciente), I (Intervenção), C (Comparação/controle) e O (Desfecho). Essa estratégia permite a formulação correta da pergunta norteadora da pesquisa, “Quais as evidências científicas acerca dos impactos psicológicos da pandemia do SARS-CoV-2 enfrentados pela população mundial?", possibilitando o melhor nível de evidências (Santos et al., 2007).

Tabela 1. Descrição da estratégia PICO. Teresina, Piauí, Brasil, 2020.

\begin{tabular}{|c|c|}
\hline ACRÔNIMO & ANÁLISE \\
\hline $\begin{array}{c}\mathrm{P} \\
\text { (Paciente) }\end{array}$ & População mundial \\
\hline $\begin{array}{c}\text { I } \\
\text { (Intervenção ou indicado) }\end{array}$ & $\begin{array}{c}\text { Intervenção ou indicador: Impactos psicológicas sofridos na } \\
\text { pandemia do SARS CoV-2 }\end{array}$ \\
\hline $\begin{array}{c}\text { C } \\
\text { (Comparação ou controle) }\end{array}$ & - \\
\hline $\begin{array}{c}\text { O } \\
\text { (Outcomes /Desfecho) }\end{array}$ & Prevenção e enfrentamento dos impactos psicológicos. \\
\hline
\end{tabular}

Fonte: Coleta de dados, Teresina-PI, 2021.

Os artigos escolhidos foram lidos para determinar quais informações seriam extraídas e usadas no presente estudo. Desenvolveu-se um formulário de categorização de artigos para armazenar dados referentes aos aspectos metodológicos e temáticos das produções, incluindo as seguintes informações: título, ano de publicação, autores, periódico de publicação e resultados das pesquisas. A interpretação e apresentação de uma síntese dos resultados basearam-se na avaliação crítica dos autores e na presença ou ausência dos sintomas de transtornos mentais desenvolvidos no atual cenário.

Ao final do processo de seleção foi encontrado um total de 398 artigos relacionados com a temática, deste total foram identificadas 143 produções no Google acadêmico, 14 na BVS, 238 na PubMed e 11 na BDENF. Após a utilização dos filtros e a leitura dos resumos e resultados foram excluídos 343 artigos e selecionados artigos completos, restando 55 artigos. Logo após a leitura dos resumos e excluindo aqueles que não atenderam aos critérios de inclusão, foram selecionados os textos completos de 19 artigos, a partir desses artigos selecionados 08 artigos foram incluídos no estudo encontrados a partir das citações; foram escritos em português, inglês e espanhol, sendo designadas 27 publicações que atenderam aos critérios de inclusão e exclusão previamente instituídos (Figura 1). Na seleção das publicações foram consideradas as recomendações do Preferred Reporting Items for Systematic Reviews and Meta-Analyses (PRISMA): dois pesquisadores independentes realizaram a seleção das publicações identificadas, avaliando criteriosamente a metodologia dos artigos considerados relevantes para o tema em estudo; a seleção ocorreu por meio dos dois pesquisadores independentes obedecendo aos critérios de inclusão e exclusão previamente definidos. 
Figura 1. Processo de seleção dos estudos. Teresina, 2021.

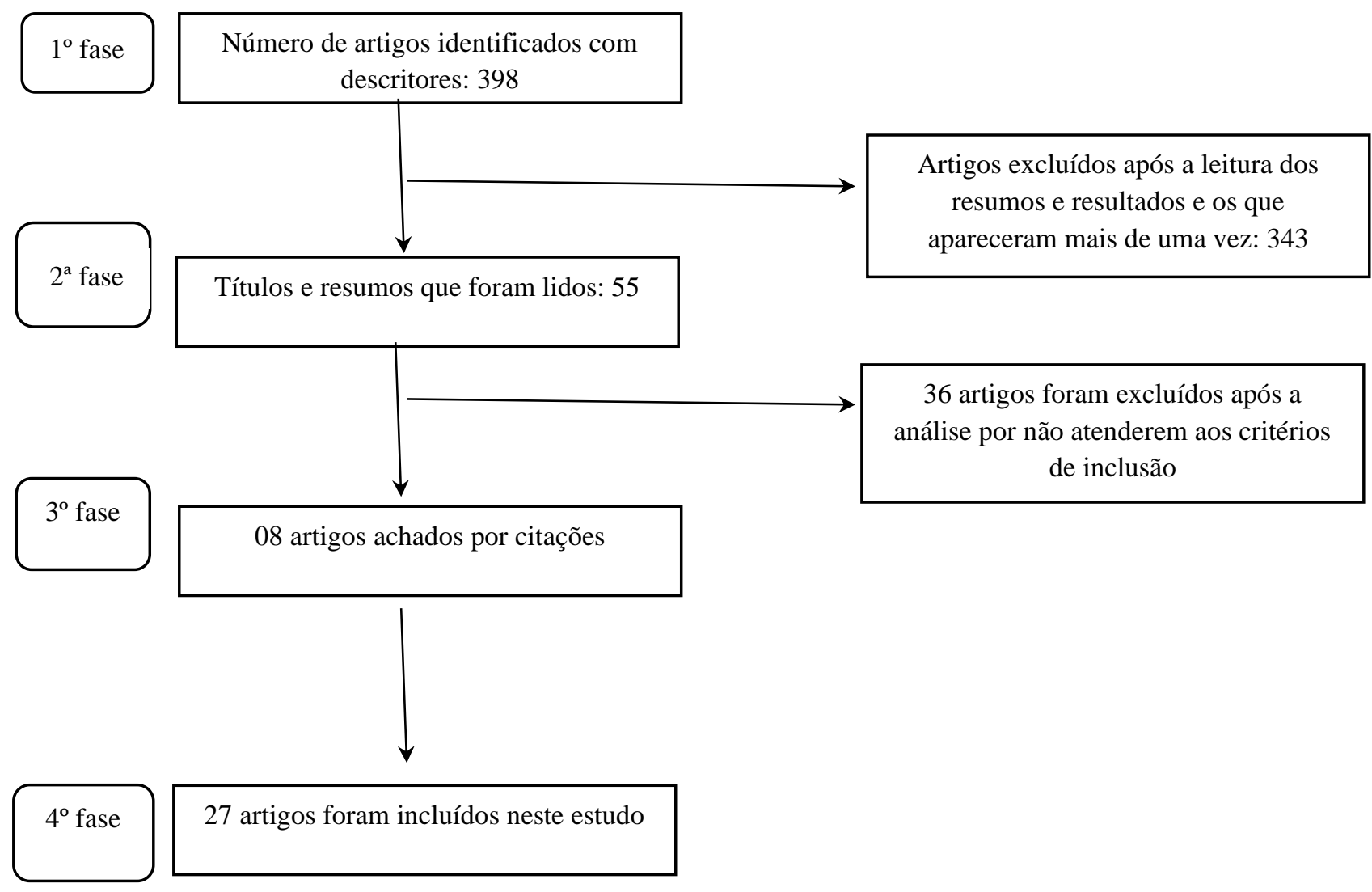

Fonte: Fluxograma das etapas da revisão integrativa recomendada pela PRISMA. Biblioteca Virtual em Saúde (BVS) (SCIELO, LILACS, BDENF, PubMed e Google Acadêmico, 2021).

Os 27 artigos selecionados foram lidos para determinar quais informações seriam extraídas, para serem usadas no presente estudo. Estes artigos foram caracterizados com o auxílio de um formulário estruturado de artigos para armazenar dados referentes aos aspectos metodológicos e temáticos dos estudos, incluindo as seguintes informações: autores, ano e local de publicação, objetivos, delineamento do estudo, objetivos e resultados da pesquisa. A análise de dados ocorreu pela leitura minuciosa, dos estudos, possibilitando a extração das principais ideias de cada autor, considerando os resultados evidenciados e as conclusões de cada publicação. Para conduzir o processo de análise foi utilizado três fases presentes desse processo analítico de acordo com de Minayo (2017): a pré-análise (etapa de leitura superficial do conteúdo para identificar as principais ideias dos artigos selecionados), exploração do material (fase de construção de grupos temáticos a partir dos conteúdos selecionados em cada pesquisa) e agrupamento dos resultados obtidos/interpretados (interpretação dos resultados e comparação com a literatura existente).

Após a coleta de dados e caracterização dos estudos selecionados, as informações foram organizadas e apresentadas em quadros e figuras; já os conteúdos descritivos das principais evidências e conclusões foram organizados em agrupamentos temáticos pela semelhança das ideias dos autores. Os resultados e as evidências das publicações foram discutidos à luz de teóricos que tratam da temática em questão e apresentadas na discussão do estudo. A presente revisão foi estruturada como artigo, seguindo-se as normas legais dispostas pela American Psychological Association (APA), estabelecendo a reprodução das 
evidências consideráveis contidas nos resultados dos artigos analisados conforme descritos, tendo em vista, a autenticidade das principais ideias apresentadas pelos seus autores, em citações diretas ou parafraseadas.

\section{Resultados}

No Quadro 1 estão presentes os 27 artigos selecionados após busca orientada pela metodologia desta pesquisa. Os estudos foram organizados de acordo com os autores, ano, título do artigo, periódico, objetivos, e resultados da pesquisa, respectivamente. Os resultados da coleta foram organizados em três quadros baseados na combinação dos descritores: Infecções por Coronavírus AND Pandemias AND Saúde AND Brasil AND Enfermagem. O tema impactos psicológicos da pandemia do SARS-CoV-2 foi encontrado em todos os estudos escolhidos e associados a diversos fatores distintos. Os resultados referentes à caracterização das publicações deste estudo foram apresentados em forma de quadros e tabelas por meio de recursos matemáticos.

Quadro 1. Caracterização dos estudos selecionados por autores, ano, título do artigo, periódico, objetivos, e resultados da publicação, Teresina-PI, 2021.

\begin{tabular}{|c|c|c|c|c|}
\hline Autores/Ano & Título do artigo & Periódico & Objetivos & Principais resultados \\
\hline $\begin{array}{l}\text { Pereira et al. } \\
(2020)\end{array}$ & $\begin{array}{l}\text { The COVID-19 pandemic, } \\
\text { social isolation, } \\
\text { consequences on mental } \\
\text { health and coping } \\
\text { strategies: an integrative } \\
\text { review. }\end{array}$ & $\begin{array}{l}\text { Research, Society } \\
\text { and Development }\end{array}$ & $\begin{array}{l}\text { Realizar uma análise sobre as } \\
\text { consequências na saúde mental } \\
\text { advindas do período de } \\
\text { isolamento social durante a } \\
\text { pandemia de COVID-19 e de } \\
\text { prenunciar estratégias de } \\
\text { enfrentamento para minimizá- } \\
\text { las. }\end{array}$ & $\begin{array}{l}\text { Os indivíduos submetidos ao isolamento } \\
\text { social estão mais suscetíveis a apresentar } \\
\text { transtornos de saúde mental, devido à } \\
\text { privação e contenção social, surgindo } \\
\text { sintomas de sofrimento psíquico, em } \\
\text { especial, relacionado ao estresse, } \\
\text { ansiedade e depressão. }\end{array}$ \\
\hline $\begin{array}{l}\text { Santana et al. } \\
(2020)\end{array}$ & $\begin{array}{lr}\text { Alterações } & \text { psicológicas } \\
\text { durante o } & \text { isolamento } \\
\text { social na } & \text { pandemia de } \\
\text { covid-19: } & \text { revisão } \\
\text { integrativa. } & \end{array}$ & $\begin{array}{l}\text { Revista Família, } \\
\text { Ciclos de Vida e } \\
\text { Saúde no } \\
\text { Contexto Social }\end{array}$ & $\begin{array}{l}\text { Compreender se o isolamento } \\
\text { social favorece o acometimento } \\
\text { de alterações psicológicas na } \\
\text { população mundial durante a } \\
\text { pandemia de COVID-19. }\end{array}$ & $\begin{array}{l}\text { As alterações psicológicas provocadas } \\
\text { pelo isolamento social mais apontadas } \\
\text { foram: ansiedade, depressão e estresse. } \\
\text { Infere-se que o isolamento social durante } \\
\text { a pandemia do COVID-19 interfere na } \\
\text { qualidade de vida das pessoas, e contribui } \\
\text { para o comprometimento da saúde } \\
\text { mental. }\end{array}$ \\
\hline $\begin{array}{l}\text { Moreira, } \\
\text { Sousa e } \\
\text { Nobrega } \\
(2020)\end{array}$ & $\begin{array}{l}\text { Adoecimento mental na } \\
\text { população geral e em } \\
\text { profissionais de saúde } \\
\text { durante a COVID-19: } \\
\text { Scoping Review }\end{array}$ & $\begin{array}{l}\text { Texto } \\
\text { Contexto- } \\
\text { Enfermagem, }\end{array}$ & $\begin{array}{lcr}\text { Mapear a } & \text { literatura } & \text { sobre } \\
\text { adoecimento } & \text { mental } & \text { na } \\
\text { população geral e } & \text { em } \\
\text { profissionais de saúde durante a } \\
\text { pandemia da Covid-19. }\end{array}$ & $\begin{array}{l}\text { A pandemia da Covid-19 desencadeou, } \\
\text { com maior frequência, ansiedade, } \\
\text { depressão, estresse e transtornos do } \\
\text { estresse pós-traumático na população } \\
\text { geral e em profissionais de saúde. } \\
\text { Mulheres, estudantes e enfermeiros estão } \\
\text { entre os mais acometidos. }\end{array}$ \\
\hline $\begin{array}{l}\text { Ortiz, } \\
\text { Quintero, } \\
\text { Córdoba, } \\
\text { Ceballos e } \\
\text { Córdoba } \\
(2020)\end{array}$ & $\begin{array}{l}\text { Consecuencias de la } \\
\text { pandemia COVID-19 en } \\
\text { la Salud Mental asociadas } \\
\text { al aislamiento social }\end{array}$ & $\begin{array}{lr}\text { New } & \text { England } \\
\text { Journal } & \text { of } \\
\text { medicine } & \end{array}$ & $\begin{array}{l}\text { Mostrar as possíveis } \\
\text { consequências na saúde mental } \\
\text { da população que pode } \\
\text { acontecer como o resultado do } \\
\text { isolamento social devido à } \\
\text { pandemia COVID-19. }\end{array}$ & $\begin{array}{l}\text { As alterações psicológicas apresentam } \\
\text { múltiplos sintomas associados que variam } \\
\text { de isolados a distúrbios complexos com } \\
\text { uma deterioração acentuada da função } \\
\text { mental, como insônia, ansiedade, } \\
\text { depressão e transtorno de estresse pós- } \\
\text { traumático. }\end{array}$ \\
\hline
\end{tabular}




\begin{tabular}{|c|c|c|c|c|}
\hline $\begin{array}{l}\text { Araujo e } \\
\text { Machado } \\
(2020)\end{array}$ & $\begin{array}{l}\text { Impact of } \\
\text { COVID-19 on } \\
\text { mental health in a } \\
\text { Low and Middle- } \\
\text { Income Country. }\end{array}$ & $\begin{array}{l}\text { Ciência \& } \\
\text { Saúde } \\
\text { Coletiva. }\end{array}$ & $\begin{array}{l}\text { Discutir os efeitos da pandemia } \\
\text { do COVID-19 em um país de } \\
\text { baixa e média renda, Brasil. }\end{array}$ & $\begin{array}{l}\text { A atual pandemia de SARS-CoV-2 está } \\
\text { afetando mais os indivíduos } \\
\text { multimórbidos, então ela é } \\
\text { particularmente problemática para } \\
\text { pessoas com transtornos mentais. } \\
\text { Compreender o ônus de um surto na saúde } \\
\text { mental é fundamental para uma ação de } \\
\text { contenção eficaz da propagação da } \\
\text { doença, pois a psicopatologia pode } \\
\text { reduzir a resistência durante o } \\
\text { confinamento. Além disso, há o estresse } \\
\text { causado pelo risco eminente de infecção } \\
\text { ou incerteza econômica, especialmente } \\
\text { em ambientes de baixa e média renda. }\end{array}$ \\
\hline $\begin{array}{l}\text { Lima et al. } \\
(2020)\end{array}$ & $\begin{array}{l}\text { Impactos no } \\
\text { comportamento e na saúde } \\
\text { mental de grupos } \\
\text { vulneráveis em época de } \\
\text { enfrentamento da infecção } \\
\text { COVID-19: revisão } \\
\text { narrativa. }\end{array}$ & $\begin{array}{l}\text { Revista Eletrônica } \\
\text { Acervo Saúde }\end{array}$ & $\begin{array}{l}\text { Realizar uma revisão narrativa } \\
\text { das repercussões no } \\
\text { comportamento e na saúde } \\
\text { mental da população vulnerável } \\
\text { e de medidas adotadas, no } \\
\text { enfrentamento da pandemia do } \\
\text { COVID-19 }\end{array}$ & $\begin{array}{l}\text { As repercussões da pandemia do COVID- } \\
19 \text { são comparadas a desastres naturais e } \\
\text { guerras, pelo receio em adoecer, ficar } \\
\text { desempregado, desamparado, ser } \\
\text { estigmatizado, caso venha a se infectar e, } \\
\text { o medo de morrer. A sensação de } \\
\text { incerteza quanto ao futuro econômico e } \\
\text { educacional traz também implicações na } \\
\text { saúde mental. Estratégias sociais, } \\
\text { educacionais, econômicas devem ser } \\
\text { implantadas para minimizar os danos } \\
\text { causados pela COVID-19. }\end{array}$ \\
\hline $\begin{array}{l}\text { Nabuco, } \\
\text { Oliveira e } \\
\text { Afonso (2020) }\end{array}$ & $\begin{array}{l}\text { O impacto da pandemia } \\
\text { pela COVID-19 na saúde } \\
\text { mental. }\end{array}$ & $\begin{array}{l}\text { Revista Brasileira } \\
\text { de Medicina de } \\
\text { Família } \\
\text { Comunidade. }\end{array}$ & $\begin{array}{l}\text { Apresentar uma proposta para a } \\
\text { atuação das equipes de Atenção } \\
\text { Primária na saúde (APS) no } \\
\text { enfrentamento ao adoecimento } \\
\text { mental relacionado à pandemia. }\end{array}$ & $\begin{array}{l}\text { Os principais fatores de risco para } \\
\text { adoecimento mental identificados } \\
\text { incluem: vulnerabilidade social, contrair a } \\
\text { doença ou conviver com alguém } \\
\text { infectado, existência de transtorno mental } \\
\text { prévio, ser idoso e ser profissional de } \\
\text { saúde. No contexto brasileiro, há ainda há } \\
\text { uma crise político-institucional } \\
\text { aumentando a ansiedade e a insegurança } \\
\text { na população. Qualificar a discussão } \\
\text { sobre o papel da APS na saúde mental da } \\
\text { população e, portanto, subsidiar ações que } \\
\text { potencializem o cuidado prestado pelas } \\
\text { equipes durante a pandemia de COVID- } \\
\text { 19. }\end{array}$ \\
\hline $\begin{array}{l}\text { Brooks et al. } \\
(2020)\end{array}$ & $\begin{array}{l}\text { The psychological } \\
\text { impact of } \\
\text { quarantine and } \\
\text { how to reduce it: } \\
\text { rapid review of } \\
\text { the evidence. }\end{array}$ & $\begin{array}{l}\text { The Lancet } \\
\text { Psychiatry }\end{array}$ & $\begin{array}{l}\text { Sugere que a o impacto da } \\
\text { quarentena é amplo e variado, } \\
\text { substancial, e pode ter uma } \\
\text { longa duração. Em situações } \\
\text { onde a quarentena for } \\
\text { considerada necessária, os } \\
\text { indivíduos devem ficar em } \\
\text { quarentena por mais tempo; } \\
\text { Fornecer justificativa para a } \\
\text { quarentena e informações sobre } \\
\text { protocolos, e garantir que } \\
\text { suprimentos suficientes sejam } \\
\text { fornecidos. Apela para }\end{array}$ & $\begin{array}{l}\text { Relataram efeitos psicológicos negativos, } \\
\text { incluindo sintomas de estresse pós- } \\
\text { traumático, confusão e raiva. Os } \\
\text { estressores incluíram quarentena mais } \\
\text { longa, medo de infecção, frustração, } \\
\text { tédio, suprimentos inadequados, } \\
\text { informações, perdas financeiras e } \\
\text { estigma. }\end{array}$ \\
\hline
\end{tabular}




\begin{tabular}{|c|c|c|c|c|}
\hline & & & $\begin{array}{l}\text { altruísmo, lembrando o público } \\
\text { sobre os benefícios da } \\
\text { quarentena para a sociedade em } \\
\text { geral, pode ser favorável. }\end{array}$ & \\
\hline $\begin{array}{l}\text { Vasconcelos, } \\
\text { Feitosa, } \\
\text { Medrado e } \\
\text { Brito (2020) }\end{array}$ & $\begin{array}{l}\text { O novo corona vírus e os } \\
\text { impactos psicologicos da } \\
\text { quarentena. }\end{array}$ & $\begin{array}{l}\text { Desafios-Revista } \\
\text { Interdisciplinar da } \\
\text { Universidade } \\
\text { Federal do } \\
\text { Tocantins }\end{array}$ & $\begin{array}{l}\text { Realizar uma análise sobre os } \\
\text { efeitos da quarentena e propor } \\
\text { estratégias para enfrentá-la, } \\
\text { além de minimizar seus efeitos. }\end{array}$ & $\begin{array}{l}\text { A quarentena pode desencadear sintomas } \\
\text { psicológicos, sendo os sintomas mais } \\
\text { comuns ansiedade, tristeza e raiva, } \\
\text { podendo ser pontuais ou se estenderem } \\
\text { após o término do isolamento. Contudo, } \\
\text { existem estratégias quando adotadas em } \\
\text { conjunto, podem minimizar os efeitos } \\
\text { psicológicos do isolamento e fazer desse } \\
\text { momento menos adoecedor. }\end{array}$ \\
\hline $\begin{array}{l}\text { Barros et al. } \\
(2020)\end{array}$ & $\begin{array}{l}\text { Relato } \\
\text { tristeza/depressão, de } \\
\text { nervosismo/ansiedade e } \\
\text { problemas de sono na } \\
\text { população adulta } \\
\text { brasileira durante a } \\
\text { pandemia de COVID-19. }\end{array}$ & $\begin{array}{l}\text { Epidemiologia e } \\
\text { Serviços de Saúde }\end{array}$ & $\begin{array}{l}\text { Analisar a frequência de tristeza, } \\
\text { nervosismo e alterações do sono } \\
\text { durante a pandemia de COVID- } \\
19 \text { no Brasil, identificando os } \\
\text { segmentos demográficos mais } \\
\text { afetados. }\end{array}$ & $\begin{array}{l}\text { A dimensão do impacto da pandemia e do } \\
\text { isolamento social sobre aspectos da saúde } \\
\text { mental e da qualidade do sono da } \\
\text { população no contexto brasileiro vem } \\
\text { almentando. O maior impacto nos adultos } \\
\text { jovens e nas mulheres sinaliza segmentos } \\
\text { demográficos de maior vulnerabilidade, a } \\
\text { demandar a aplicação e o aprimoramento } \\
\text { das estratégias de preservação e atenção à } \\
\text { saúde mental durante a pandemia. Os } \\
\text { resultados ressaltam que as pessoas com } \\
\text { antecedentes de depressão são as mais } \\
\text { vulneráveis no contexto pandêmico. }\end{array}$ \\
\hline $\begin{array}{l}\text { Schmidt, } \\
\text { Crepaldi, } \\
\text { Bolze, Silva e } \\
\text { Demenech } \\
(2020)\end{array}$ & $\begin{array}{l}\text { Impactos na saúde } \\
\text { mental e } \\
\text { intervenções } \\
\text { psicológicas } \\
\text { diante da } \\
\text { pandemia do novo } \\
\text { coronavírus } \\
\text { (COVID-19). }\end{array}$ & $\begin{array}{l}\text { Estudos } \\
\text { Psicologi } \\
\text { a } \\
\text { (Campina } \\
\text { s), }\end{array}$ & $\begin{array}{l}\text { Sistematizar conhecimentos } \\
\text { sobre implicações na saúde } \\
\text { mental e intervenções } \\
\text { psicológicas diante da pandemia } \\
\text { do novo coronavírus. }\end{array}$ & $\begin{array}{l}\text { A Psicologia pode oferecer contribuições } \\
\text { importantes para o enfrentamento das } \\
\text { repercussões da COVID-19. sugerimos } \\
\text { levantamentos sobre os impactos na saúde } \\
\text { mental diante da pandemia e sobre } \\
\text { intervenções psicológicas alinhadas às } \\
\text { necessidades do contexto brasileiro, } \\
\text { considerando as características de } \\
\text { diferentes populações. }\end{array}$ \\
\hline $\begin{array}{l}\text { Accorsi, } \\
\text { Santos, } \\
\text { Accorsi, } \\
\text { Bohac e Chin } \\
(2020)\end{array}$ & $\begin{array}{l}\text { COVID-19 e o } \\
\text { Sistema Nervoso } \\
\text { Central. }\end{array}$ & $\begin{array}{l}\text { Revista } \\
\text { Ulakes }\end{array}$ & $\begin{array}{l}\text { Realizar uma revisão sobre a } \\
\text { patogenia da COVID-19 no } \\
\text { sistema nervoso central, com } \\
\text { ênfase na teoria da tempestade } \\
\text { de citocinas. }\end{array}$ & $\begin{array}{l}\text { Nas infecções por SARS-CoV foram } \\
\text { relatadas manifestações centrais como } \\
\text { ansiedade, rebaixamento dos níveis de } \\
\text { consciência, no caso de SARS-CoV-2, } \\
\text { foram observados além dos efeitos } \\
\text { centrais já relatados, outras manifestações } \\
\text { neurológicas como meningite, e que as } \\
\text { manifestações neurológicas advindas da } \\
\text { infecção pelo vírus SARS-CoV-2 estão } \\
\text { relacionadas com a neuroinflamação que } \\
\text { evolui com a tempestade de citocinas. }\end{array}$ \\
\hline $\begin{array}{l}\text { Oliveira, } \\
\text { Ayres, Reis, } \\
\text { Toledo e Silva } \\
(2020)\end{array}$ & $\begin{array}{l}\text { Lêvitude } \\
\text { emocional e as } \\
\text { estratégias da } \\
\text { Teoria Cognitivo- } \\
\text { Comportamental } \\
\text { para o }\end{array}$ & $\begin{array}{l}\text { Revista } \\
\text { Enfermag } \\
\text { em e } \\
\text { Saúde } \\
\text { Coletiva- } \\
\text { REVESC }\end{array}$ & $\begin{array}{l}\text { Realizar uma análise sobre as } \\
\text { estratégias de enfrentamento a } \\
\text { partir da teoria cognitivo- } \\
\text { comportamental para minimizá- } \\
\text { lo. }\end{array}$ & $\begin{array}{l}\text { A terapia cognitivo-comportamental tem } \\
\text { muito a contribuir com situações de crises } \\
\text { e tragédias sociais. Atuar na prevenção de } \\
\text { condições psicopatológicas. Estrategias } \\
\text { como: regulação emocional (como a } \\
\text { habilidade de manter, aumentar ou } \\
\text { diminuir um ou mais componentes da }\end{array}$ \\
\hline
\end{tabular}


Research, Society and Development, v. 10, n. 6, e50010616286, 2021

(CC BY 4.0) | ISSN 2525-3409 | DOI: http://dx.doi.org/10.33448/rsd-v10i6.16286

\begin{tabular}{|c|c|c|c|c|}
\hline & $\begin{array}{l}\text { enfrentamento do } \\
\text { COVID- } 19 .\end{array}$ & & & $\begin{array}{l}\text { resposta emocional), reestruturação } \\
\text { cognitiva (escolhas conscientes do } \\
\text { paciente), autoestima, assertividade e } \\
\text { resiliência, parada de pensamentos e } \\
\text { descatastrofização, cuidado com excesso } \\
\text { de informações, estabelecer rotina de } \\
\text { atividades, }\end{array}$ \\
\hline $\begin{array}{l}\text { Talevi et al. } \\
\text { (2020) }\end{array}$ & $\begin{array}{l}\text { Mental health } \\
\text { outcomes of the } \\
\text { CoViD-19 } \\
\text { pandemic. }\end{array}$ & $\begin{array}{l}\text { Rivista di } \\
\text { psichiatri } \\
\text { a }\end{array}$ & $\begin{array}{l}\text { Resumir a literatura relevante } \\
\text { sobre o impacto psicológico da } \\
\text { pandemia CoViD-19 em as } \\
\text { populações afetadas. }\end{array}$ & $\begin{array}{l}\text { A pandemia de Covid-19, está tendo um } \\
\text { enorme impacto psicológico nos } \\
\text { indivíduos. A maioria dos indivíduos } \\
\text { sofria de distúrbios moderados, enquanto } \\
\text { os sujeitos que relatam severos sintomas } \\
\text { eram uma minoria. Algumas categorias se } \\
\text { mostraram mais vulneráveis, ou seja, } \\
\text { profissionais de saúde e pacientes } \\
\text { afetados pelo CoViD-19. Nos observados } \\
\text { a prevalência não era homogênea, sexo } \\
\text { feminino e idade mais jovem foram } \\
\text { associados com maior risco para os } \\
\text { resultados da saúde mental. }\end{array}$ \\
\hline $\begin{array}{l}\text { Gao et al. } \\
(2020)\end{array}$ & $\begin{array}{l}\text { Mental health problems } \\
\text { and social media exposure } \\
\text { during } \quad \text { COVID-19 } \\
\text { outbreak }\end{array}$ & Journal Plos one & $\begin{array}{l}\text { Descrever a prevalência e } \\
\text { distribuição de dois grandes } \\
\text { transtornos mentais: ansiedade e } \\
\text { depressão entre a população } \\
\text { chinesa, e examinar suas } \\
\text { associações com exposição nas } \\
\text { redes sociais por avaliação } \\
\text { rápida durante o surto de Covid- } \\
19 .\end{array}$ & $\begin{array}{l}\text { Há alta prevalência de problemas de } \\
\text { saúde mental, que positivamente } \\
\text { associada com SME (Social media } \\
\text { exposure / Exposição nas redes sociais), } \\
\text { frequentemente durante o surto de } \\
\text { COVID-19. Estes achados implicaram } \\
\text { que o governo precisa prestar mais } \\
\text { atenção à saúde mental entre a população } \\
\text { em geral. A próxima implicação é } \\
\text { combater a "infodemia" monitorando e } \\
\text { filtrando informações falsas, informação } \\
\text { e promoção de informações precisas } \\
\text { através de colaborações transversais. }\end{array}$ \\
\hline $\begin{array}{l}\text { Silva, Jorge e } \\
\text { Luzeiro } \\
(2020)\end{array}$ & $\begin{array}{l}\text { Manifestações } \\
\text { Neurológicas em } \\
\text { Doentes com } \\
\text { Infeção por } \\
\text { SARS-CoV-2 }\end{array}$ & Sinapse & $\begin{array}{l}\text { Rever os dados disponíveis até o } \\
\text { ano de } 2020 \text { sobre as } \\
\text { manifestações neurológicas } \\
\text { associadas à infeção por SARS- } \\
\text { CoV-2, identificando possíveis } \\
\text { mecanismos fisiopatológicos e } \\
\text { abordagem. }\end{array}$ & $\begin{array}{l}\text { Descoberta das potenciais manifestações } \\
\text { neurológicas associadas à infeção por } \\
\text { SARS-CoV-2. Os trabalhos tendem a ser } \\
\text { maioritariamente observacionais, com } \\
\text { amostras pequenas, o que limita as } \\
\text { conclusões possíveis. Trata-se de um } \\
\text { cenário novo, prevendo-se um impacto } \\
\text { social, económico e cultural, profundo. }\end{array}$ \\
\hline $\begin{array}{l}\text { Artal } \\
(2020 \\
)\end{array}$ & \begin{tabular}{lr}
\multicolumn{2}{l}{ Complicaciones } \\
neurológicas & por \\
coronavirus & $y$ \\
COVID-19. & \\
Revista & de \\
Neurología &
\end{tabular} & $\begin{array}{ll}\text { Revista } & \text { de } \\
\text { Neurología } & \end{array}$ & $\begin{array}{l}\text { Analisa os dados disponíveis } \\
\text { sobre as complicações } \\
\text { neurológicas do virus em geral e } \\
\text { SARS-CoV-2 em particular. }\end{array}$ & $\begin{array}{l}\text { Fatores virais (mutações em genes } \\
\text { específicos que aumentam a virulência de } \\
\text { SARS-CoV-2) e fatores associados ao } \\
\text { hospedeiro (idade avançada, } \\
\text { comorbilidades, imunossupressão), bem } \\
\text { como a interação entre o vírus e o } \\
\text { hospedeiro, são as condições apropriadas } \\
\text { que podem explicar os diferentes níveis } \\
\text { de neurotropismo, invasão do SNC e } \\
\text { neurovirulento de SARS-CoV-2 em } \\
\text { humanos. A incidência de complicações }\end{array}$ \\
\hline
\end{tabular}




\begin{tabular}{|c|c|c|c|c|}
\hline & & & & $\begin{array}{l}\text { neurológicas, seu tipo e gravidade ainda } \\
\text { são incertos. }\end{array}$ \\
\hline $\begin{array}{l}\text { Moreira et al. } \\
(2020)\end{array}$ & $\begin{array}{lr}\text { Intervenções } & \text { em saúde } \\
\text { mental em } & \text { tempos de } \\
\text { COVID-19: } & \text { scoping } \\
\text { review } & \end{array}$ & $\begin{array}{l}\text { Health } \\
\text { Sciences }\end{array}$ & $\begin{array}{l}\text { Mapear as evidências sobre } \\
\text { intervenções em saúde mental } \\
\text { implementadas durante a } \\
\text { pandemia da COVID-19, com } \\
\text { intuito de fornecer à população e } \\
\text { aos profissionais de saúde } \\
\text { mecanismos para } \quad \text { o } \\
\text { enfrentamento dos impactos } \\
\text { dessa pandemia à saúde mental. }\end{array}$ & $\begin{array}{l}\text { As evidências enfatizam as intervenções } \\
\text { de cuidados em saúde mental } \\
\text { direcionadas a grupos populacionais } \\
\text { diversos no contexto pandêmico da } \\
\text { COVID-19, nomeadamente: } \\
\text { telemonitoramento, jogos virtuais e } \\
\text { intervenções focalizadas no suporte social } \\
\text { e em técnicas de relaxamento muscular. } \\
\text { não farmacológicas e de baixo custo e } \\
\text { necessitam ser incentivadas e incluídas } \\
\text { nos cenários de atenção à saúde mental. }\end{array}$ \\
\hline $\begin{array}{l}\text { Ahmed et al. } \\
\text { (2020) }\end{array}$ & $\begin{array}{l}\text { Epidemic of } \\
\text { COVID-19 in } \\
\text { China and } \\
\text { Associated } \\
\text { Psychological } \\
\text { Problems. }\end{array}$ & $\begin{array}{l}\text { Asian Journal of } \\
\text { Psychiatry }\end{array}$ & $\begin{array}{l}\text { Avaliar o estado de saúde mental } \\
\text { dos chineses. }\end{array}$ & $\begin{array}{l}\text { O estudo evidenciou maior taxa de } \\
\text { ansiedade, depressão, uso de álcool } \\
\text { perigoso e prejudicial e menor bem-estar } \\
\text { mental do que a proporção habitual. } \\
\text { Mostrou também que os jovens de } 21 \text { a } 40 \\
\text { anos estão em posição mais vulnerável em } \\
\text { termos de suas condições de saúde mental } \\
\text { e uso de álcool. }\end{array}$ \\
\hline $\begin{array}{l}\text { Asmundson e } \\
\text { Taylor (2020) }\end{array}$ & $\begin{array}{l}\text { Coronaphobia: Fear and } \\
\text { the 2019-nCoV outbreak. }\end{array}$ & $\begin{array}{l}\text { Journal of anxiety } \\
\text { disorders }\end{array}$ & $\begin{array}{l}\text { Analisar as consequências } \\
\text { psicossociais do COVID-19, } \\
\text { como medo excessivo (ou falta } \\
\text { de preocupação e devida } \\
\text { cautela) e discriminação, e } \\
\text { encontrar evidências que } \\
\text { abordam essas questões. }\end{array}$ & $\begin{array}{l}\text { Um terço dos entrevistados estava } \\
\text { preocupado com o vírus e } 7 \% \text { estavam } \\
\text { "muito preocupados" em se infectar. } \\
\text { Consistente com os achados de epidemias } \\
\text { e pandemias anteriores, muitas pessoas } \\
\text { nesta pesquisa ( } 33 \% \text { ) não se mostraram } \\
\text { confiantes de que o sistema de saúde em } \\
\text { sua comunidade estava preparado para } \\
\text { lidar com novos casos do coronavírus. }\end{array}$ \\
\hline $\begin{array}{l}\text { Duan e Zhu } \\
(2020)\end{array}$ & $\begin{array}{l}\text { Psychological } \\
\text { interventions for people } \\
\text { affected by the COVID-19 } \\
\text { epidemic. }\end{array}$ & $\begin{array}{l}\text { The Lancet } \\
\text { Psychiatry }\end{array}$ & $\begin{array}{l}\text { Avaliar os estados de saúde } \\
\text { mental dos indivíduos afetados } \\
\text { pela epidemia do SARS-CoV-2, } \\
\text { de acordo com a gravidade de } \\
\text { sua condição e dificuldade de } \\
\text { tratamento oportunos e } \\
\text { razoáveis. }\end{array}$ & $\begin{array}{l}\text { Indivíduos que vivenciaram emergências } \\
\text { em saúde pública ainda possuem } \\
\text { diferentes graus de transtornos de } \\
\text { estresse, mesmo após o fim do evento. } \\
\text { Portanto, deve-se considerar o curso da } \\
\text { doença, a gravidade dos sintomas } \\
\text { clínicos, o local de tratamento e outros } \\
\text { fatores para classificar indivíduos que } \\
\text { necessitam de intervenção psicológica e } \\
\text { formular medidas específicas para } \\
\text { melhorar a eficácia dessas intervenções. }\end{array}$ \\
\hline $\begin{array}{l}\text { Lai et al. } \\
(2020)\end{array}$ & $\begin{array}{l}\text { Factors associated with } \\
\text { mental health outcomes } \\
\text { among health care } \\
\text { workers exposed to } \\
\text { coronavirus disease } 2019 .\end{array}$ & $\begin{array}{l}\text { JAMA network } \\
\text { open }\end{array}$ & $\begin{array}{l}\text { Avaliar a magnitude dos } \\
\text { desfechos de saúde mental e os } \\
\text { fatores associados entre os } \\
\text { profissionais de saúde que } \\
\text { tratam pacientes expostos ao } \\
\text { COVID-19 na China. }\end{array}$ & $\begin{array}{l}\text { Uma proporção considerável de } \\
\text { profissionais de saúde relatou sentir } \\
\text { sintomas de depressão, ansiedade, insônia } \\
\text { e angústia, especialmente mulheres, } \\
\text { enfermeiros, pessoas em Wuhan e } \\
\text { profissionais de saúde de linha de frente } \\
\text { diretamente envolvidos no diagnóstico, } \\
\text { tratamento ou prestação de cuidados de } \\
\text { enfermagem a pacientes com COVID-19 } \\
\text { suspeitos ou confirmados. }\end{array}$ \\
\hline
\end{tabular}




\begin{tabular}{|c|c|c|c|c|}
\hline $\begin{array}{l}\text { Holmes et al. } \\
(2020)\end{array}$ & $\begin{array}{l}\text { Multidisciplinary } \\
\text { research } \\
\text { priorities for the } \\
\text { COVID-19 } \\
\text { pandemic: a call } \\
\text { for action for } \\
\text { mental health } \\
\text { science. }\end{array}$ & $\begin{array}{l}\text { The } \\
\text { Lancet } \\
\text { Psychiatr } \\
y \text {, }\end{array}$ & $\begin{array}{l}\text { Analisar os efeitos psicológicos, } \\
\text { sociais e neurocientíficos do } \\
\text { COVID-19 e coletar dados de } \\
\text { alta qualidade sobre os efeitos da } \\
\text { pandemia em toda a população e } \\
\text { grupos vulneráveis, e sobre a } \\
\text { função cerebral, cognição e } \\
\text { saúde mental de pacientes com } \\
\text { COVID-19. }\end{array}$ & $\begin{array}{l}\text { Os efeitos psicológicos, sociais e } \\
\text { neurocientíficos do COVID-19 foram } \\
\text { estabelecidas prioridades imediatas e } \\
\text { estratégias de longo prazo para a pesquisa } \\
\text { em ciência da saúde mental. Essas } \\
\text { prioridades foram informadas por } \\
\text { pesquisas do público e de um painel de } \\
\text { especialistas convocado pela Academia } \\
\text { de Ciências Médicas do Reino Unido e } \\
\text { pela instituição de pesquisa em saúde } \\
\text { mental MQ: Transforming Mental Health, } \\
\text { nas primeiras semanas da pandemia no } \\
\text { Reino Unido, em março de } 2020 \text {. }\end{array}$ \\
\hline $\begin{array}{l}\text { Liu et al. } \\
(2020)\end{array}$ & $\begin{array}{l}\text { Online mental health } \\
\text { services in China during } \\
\text { the COVID-19 outbreak. }\end{array}$ & $\begin{array}{l}\text { The Lancet } \\
\text { Psychiatry }\end{array}$ & $\begin{array}{l}\text { Avaliar os serviços de saúde } \\
\text { mental on-line que estão sendo } \\
\text { utilizados para a epidemia } \\
\text { COVID-19; Promover } \\
\text { intervenções que melhorem a } \\
\text { qualidade e a eficácia das } \\
\text { intervenções emergenciais. }\end{array}$ & $\begin{array}{l}\text { A popularização dos serviços de internet } \\
\text { e smartphones, e o surgimento de redes } \\
\text { móveis de quinta geração (5G), } \\
\text { permitiram que profissionais de saúde } \\
\text { mental e autoridades de saúde } \\
\text { fornecessem serviços online de saúde } \\
\text { mental durante o surto de COVID-19. } \\
\text { Como atendimentos online, com os } \\
\text { profissionais. }\end{array}$ \\
\hline $\begin{array}{l}X u \quad \text { et al. } \\
(2020)\end{array}$ & $\begin{array}{l}\text { Pathological findings of } \\
\text { COVID-19 associated } \\
\text { with acute respiratory } \\
\text { distress syndrome. }\end{array}$ & $\begin{array}{l}\text { The Lancet } \\
\text { respiratory } \\
\text { medicine }\end{array}$ & $\begin{array}{l}\text { Facilitar a compreensão da } \\
\text { patogênese do COVID-19 e } \\
\text { melhorar as estratégias clínicas } \\
\text { contra a doença. China }\end{array}$ & $\begin{array}{l}\text { A superativação das células } \mathrm{T} \text {, } \\
\text { manifestada pelo aumento de Th17 e alta } \\
\text { citotoxicidade das células CD } 8 \mathrm{~T} \text {, explica, } \\
\text { em parte, a grave lesão imunológica neste } \\
\text { paciente. }\end{array}$ \\
\hline $\begin{array}{l}\text { Wang et al. } \\
(2020)\end{array}$ & $\begin{array}{l}\text { Immediate psychological } \\
\text { responses and associated } \\
\text { factors during the initial } \\
\text { stage of the } 2019 \\
\text { coronavirus disease } \\
\text { (COVID-19) epidemic } \\
\text { among the general } \\
\text { population in China. }\end{array}$ & $\begin{array}{l}\text { International } \\
\text { journal of } \\
\text { environmental } \\
\text { research and } \\
\text { public health. }\end{array}$ & $\begin{array}{l}\text { Pesquisar o público em geral na } \\
\text { China para entender melhor seus } \\
\text { níveis de impacto psicológico, } \\
\text { ansiedade, depressão e estresse } \\
\text { durante o estágio inicial do surto } \\
\text { de COVID-19. }\end{array}$ & $\begin{array}{l}\text { Durante a fase inicial do surto de COVID- } \\
19 \text { na China, mais da metade dos } \\
\text { entrevistados avaliaram seu impacto } \\
\text { psicológico como moderado a grave, e } \\
\text { cerca de um terço relatou ansiedade de } \\
\text { moderado a grave. O gênero feminino, e } \\
\text { estudantes foram associados a um maior } \\
\text { impacto psicológico do surto e níveis } \\
\text { mais elevados de estresse e ansiedade }\end{array}$ \\
\hline $\begin{array}{l}\text { Castro et al. } \\
(2020)\end{array}$ & $\begin{array}{l}\text { Influencia de la infección } \\
\text { SARS-CoV-2 sobre } \\
\text { enfermedades } \\
\text { neurodegenerativas y } \quad \text { neuropsiquiátricas: una } \\
\text { neundemia demorada? }\end{array}$ & $\begin{array}{l}\text { Revista } \\
\text { Neurología }\end{array}$ & $\begin{array}{l}\text { Estudar possíveis consequências } \\
\text { na patologia neurológica a } \\
\text { médio e longo prazo, com } \\
\text { especial atenção para doenças } \\
\text { neurodegenerativas } \\
\text { neuropsiquiátricas de base } \\
\text { neuroinflamatória. }\end{array}$ & $\begin{array}{l}\text { A SARS-CoV-2 é um vírus neuroinvasivo } \\
\text { capaz de desencadear uma tempestade de } \\
\text { citocinas, com efeitos persistentes em } \\
\text { populações específicas. Os impactos que } \\
\text { este movimento molecular poderia ter no } \\
\text { início e progressão a doença de } \\
\text { Alzheimer, Parkinson ou esclerose } \\
\text { múltipla em sua fase neurodegenerativa. }\end{array}$ \\
\hline
\end{tabular}

Fonte: Biblioteca Virtual em Saúde (BVS) (SCIELO, LILACS, BDENF, PubMed e Google Acadêmico), Teresina-PI, 2021.

A Tabela 1 agrupa as variáveis país, ano, periódicos de publicação e abordagem metodológica. A maioria dos estudos localizados foram estrangeiros, totalizando 15 publicações, correspondendo a 55,5\% das produções encontradas nas bases de dados virtuais, destacando-se a China com 18,51\%, Espanha com 7,40 \%, Colômbia 3,40\%, Itália com 3,70\%, Portugal 3,70\%, Canadá 3,70\%, Reino Unido 3,70\%, Japão 3,70\%, Londres 3,70\%, Ásia 3,70\%. Apesar do maior quantitativo de publicações ser 
internacional, dentre todos os países identificados separadamente no estudo, foi no Brasil onde constatou-se mais produções sobre a temática com (12) artigos, correspondendo a 44,4\% do total da amostra.

Pode-se observar que todas as publicações referentes ao tema foram em 2020. Os periódicos estrangeiros que mais se destacaram foram The Lancet Psychiatry com 14,81\%, e Health Sciences com 7,40\%, já os nacionais apareceram todos com $3,70 \%$ revelando que os dados possuem cientificidade, impacto e seguem os princípios éticos na pesquisa. Quanto à abordagem metodológica a que mais se destacou foi a revisão integrativa com 22,2\% seguida da revisão sistemática com 18,51\% e o estudo observacional 14,81\%, estudos quantitativa, quantitativos, revisão narrativa e revisão de escopo apresentaram-se com os mesmos percentuais $7,40 \%$, já o relato de experiência, estudo reflexivo, pesquisa teórico-prática e ensaio científico apareceram com $3,70 \%$,

Tabela 1. Distribuição das produções científicas segundo as variáveis: país, ano, periódicos, fator de impacto e delineamento do estudo. Teresina - PI, 2020.

\begin{tabular}{|c|c|c|}
\hline Variáveis & $\mathbf{N}^{\mathbf{o}}$ & $\%$ \\
\hline \multicolumn{3}{|l|}{ País } \\
\hline Brasil & 12 & $44,44 \%$ \\
\hline China & 05 & $18,51 \%$ \\
\hline Espanha & 02 & $7,40 \%$ \\
\hline Colômbia & 01 & $3,70 \%$ \\
\hline Itália & 01 & $3,70 \%$ \\
\hline Portugal & 01 & $3,70 \$$ \\
\hline Canadá & 01 & $3,70 \%$ \\
\hline Reino Unido & 01 & $3,70 \%$ \\
\hline Japão & 01 & $3,70 \%$ \\
\hline Londres & 01 & $3,70 \%$ \\
\hline Ásia & 01 & $3,70 \%$ \\
\hline \multicolumn{3}{|l|}{ Ano } \\
\hline 2020 & 27 & $100 \%$ \\
\hline \multicolumn{3}{|l|}{ Periódico } \\
\hline $\begin{array}{l}\text { Research, Society and } \\
\text { Development }\end{array}$ & 01 & $3,70 \%$ \\
\hline $\begin{array}{l}\text { Revista Família, Ciclos de Vida } \\
\text { e Saúde no Contexto Social }\end{array}$ & 01 & $3,70 \%$ \\
\hline Texto \& Contexto-Enfermagem & 01 & $3,70 \%$ \\
\hline $\begin{array}{l}\text { New England Journal of } \\
\text { Medicine }\end{array}$ & 01 & $3,70 \%$ \\
\hline Ciência \& Saúde Coletiva & 01 & $3,70 \%$ \\
\hline $\begin{array}{l}\text { Revista Eletrônica } \quad \text { Acervo } \\
\text { Saúde }\end{array}$ & 01 & $3,70 \%$ \\
\hline $\begin{array}{l}\text { RBMFC-Revista } \text { Brasileira de } \\
\text { Medicina de Família e } \\
\text { Comunidade }\end{array}$ & 01 & $3,70 \%$ \\
\hline The Lancet Psychiatry & 04 & $14,81 \%$ \\
\hline
\end{tabular}


Research, Society and Development, v. 10, n. 6, e50010616286, 2021

(CC BY 4.0) | ISSN 2525-3409 | DOI: http://dx.doi.org/10.33448/rsd-v10i6.16286

Revista Interdisciplinar da

01

$3,70 \%$

Universidade Federal do

Tocantins

Epidemiologia e Serviços de

Saúde

Estudos de Psicologia

(Campinas)

Revista Ulakes

o

, $70 \%$

01

$3,70 \%$

REVESC-Revista Enfermagem

e Saúde Coletiva

Rivista di psichiatria

01

$3,70 \%$

01

$3,70 \%$

01

$3,70 \%$

Journal Plos one

01

$3,70 \%$

Sinapse

01

$3,70 \%$

Revista de Neurología

$3,70 \%$

Health Sciences

$3,70 \%$

Asian Journal of Psychiatry

$7,40 \%$

Journal of anxiety disorders

$3,70 \%$

Jama Network Open

$3,70 \%$

The Lancet Respiratory

Medicine

$3,70 \%$

International Journal of

Environmental

Research and Public Health

01

$3,70 \%$

\begin{tabular}{lcc}
\hline Abordagem metodológica & & \\
\hline Revisão integrativa & 06 & $22,22 \%$ \\
Relato de Experiência & 01 & $3,70 \%$ \\
Revisão Sistemática & 03 & $18,51 \%$ \\
Quantitativa & 02 & $7,40 \%$ \\
Qualitativa & 02 & $7,40 \%$ \\
Revisão Narrativa & 02 & $7,40 \%$ \\
Revisão de Escopo & 02 & $7,40 \%$ \\
Estudo Observacional & 04 & $14,81 \%$ \\
Estudo Reflexivo & 01 & $3,70 \%$ \\
Pesquisa teórico-prática & 01 & $3,70 \%$ \\
Ensaio científico & 01 & $3,70 \%$ \\
\hline
\end{tabular}

Fonte: Pesquisa direta em base de dados, Teresina, 2021.

O Quadro 2, representa os subtítulos utilizados na discussão dos artigos selecionados, para facilitar o entendimento e a explanação do conteúdo abaixo. O foco do estudo, envolveu três subtemas: Impactos do vírus na saúde mental da população; Fatores desencadeadores dos problemas de saúde mental durante a pandemia e as Estratégias para mitigar os efeitos à saúde mental. 
Quadro 2. Distribuição dos artigos em Foco do estudo e Identificação dos Artigos.

\begin{tabular}{|c|c|}
\hline FOCO DO ESTUDO & IDENTIFICAÇÃO DOS ARTIGOS POR AUTORES \\
\hline $\begin{array}{l}\text { Impactos do vírus na saúde mental da população } \\
\text {-Depressão } \\
\text {-Ansiedade } \\
\text {-Estresse pós-traumático, } \\
\text {-Pânico } \\
\text {-Confusão } \\
\text {-Raiva } \\
\text {-Medo }\end{array}$ & $\begin{array}{l}\text { (Wang et al., 2020); (Ahmed et al., 2020); (Pereira et al., } \\
\text { 2020); (Barros et al., 2020); (Lai et al., 2020); (Castro et al., } \\
\text { 2020); (Xu et al., 2020); (ACCORSI et al., 2020); (SILVA } \\
\text { et al., 2020); (Duan \& Zhu, 2020); (Holmes et al., 2020); } \\
\text { (Artal, 2020) }\end{array}$ \\
\hline $\begin{array}{l}\text { Fatores desencadeadores dos problemas de saúde mental } \\
\text { durante a pandemia } \\
\text {-Disseminação de informações falsas } \\
\text {-Preocupações com a escassez de suprimentos } \\
\text {-Perdas financeiras } \\
\text {-Medo de ser infectado pelo vírus }\end{array}$ & $\begin{array}{l}\text { (Santana., et al., 2020); (Brooks et al., 2020); (Lima et al., } \\
\text { 2020); (Pereira et al., 2020); (Asmundson \& Taylon, 2020) }\end{array}$ \\
\hline $\begin{array}{l}\text { Estratégias para mitigar os efeitos à saúde mental } \\
\text {-Prática de atividade física } \\
\text {-Apoio emocional presencial ou online } \\
\text {-Acesso aos medicamentos e serviços de aconselhamento } \\
\text {-Manter o sono regular }\end{array}$ & $\begin{array}{l}\text { (Ortiz, Quintero, Córdoba, Ceballos, \& Córdoba, 2020); } \\
\text { (Nabuco, Oliveira, \& Afonso, 2020); (Moreira, Sousa, \& } \\
\text { Nobrega, 2020); (Araújo \& Machado, 2020); (Oliveira et } \\
\text { al, 2020); (Talevi et al, 2020); (Gao et al, 2020); (Wang et } \\
\text { al., 2020); (Schmidt et al. 2020);(Liu et al., 2020); } \\
\text { (Moreira et al., 2020); }\end{array}$ \\
\hline
\end{tabular}

Fonte: Pesquisa direta em base de dados, Teresina, 2021.

\section{Discussão}

\subsection{Impactos do vírus na saúde mental da população}

O impacto global da pandemia no sistema de saúde, na política, economia e educação, assim como as notícias orais e escritas que exploram esse tema, têm mostrado constantemente um grande número de pessoas que contraem e morrem de COVID-19 todos os dias, o que pode acarretar desequilíbrios psicológicos, como pânico na multidão. Apesar de todas as repercussões biopsicossociais já evidenciadas em estudos científicos e noticiadas pela mídia, o impacto desta pandemia ainda não recebeu atenção necessária quanto às implicações psicológicas e mentais. Sintomas de depressão, ansiedade e estresse diante deste momento pandêmico têm sido identificados na população geral (Wang et al., 2020). Do mesmo modo, pacientes suspeitos, infectados com o vírus da COVID-19, bem como, profissionais da saúde, de serviços essenciais e outros indivíduos em contato próximo com os pacientes afetados estão também nos grupos propícios a danos à saúde mental como ansiedade, depressão, medo do contágio ou morte (Ahmed et al., 2020).

Estudos realizados por Wang et al. (2020) relatam que devido à distância da família e das relações sociais e ao risco iminente de contaminação pelo SARS CoV-2, não apenas os pacientes, mas toda a população (idosos, moradores de casa de repouso, mulheres e outros) é afetada mentalmente devido à situação imposta a todos. Portanto, a maioria das pessoas estão se sentindo entediada, decepcionada, irritada e com emoções negativas devido às medidas de isolamento, principalmente pacientes 
Research, Society and Development, v. 10, n. 6, e50010616286, 2021

(CC BY 4.0) | ISSN 2525-3409 | DOI: http://dx.doi.org/10.33448/rsd-v10i6.16286

que apresentam esquizofrenia, transtornos de ansiedade e sintomas de depressão. Pereira et al. (2020) corroboram com esses achados e observaram que os sintomas psicológicos mais comuns são causados principalmente pelo estresse, medo, pânico, ansiedade, culpa e tristeza, ocasionando profundo sofrimento psicológico que pode causar psicopatologias como transtorno do pânico e de ansiedade, transtorno de estresse pós-traumático (TEPT) e depressão.

Contudo, Barros et al. (2020), ao realizar pesquisa nacional, constataram que quase metade da população mundial, dentre ela, adultos, jovens, mulheres e pessoas que foram previamente diagnosticadas com depressão tiveram sentimento de tristeza e se sentiram deprimidos, além de sintomas de ansiedade, nervosismo e problemas de sono, sendo que nas pessoas que já tinham problemas, agravou-se mais ainda. É sabido que a pandemia trouxe um pânico global na saúde mental das pessoas que tinham suas vidas agitadas devido às características da contemporaneidade, acarretando assim, medo e aflição em contrair a doença e excesso de informações veiculadas na mídia, espalhando medo e pânico (Bagcchi, 2020).

Contudo, Barros et al. (2020) constata em seus estudos que quase metade da população mundial, dentre eles, adultos, jovens, mulheres e pessoas que foram previamente diagnosticadas com depressão tiveram sentimento de tristeza e se sentiram deprimidos, além de sintomas de ansiedade, nervosismo e problemas de sono, sendo que nas pessoas que já tinham problemas, agravou-se mais ainda.

Baseado em estudo com a população chinesa, Lai et al. (2020) ressaltam em suas pesquisas que essas repercussões emocionais atingem também os profissionais de serviços essenciais, destacando-se os profissionais de saúde que estão sob muita pressão pois estão em contato direto e frequente com pacientes infectados pelo SARS CoV-2, tornando-os mais propensos a contraírem a doença, quanto aos adoecimento psíquico pela tensão gerada pelo medo, insegurança, cansaço e esforços físicos e psicológicos intensos. Além dos riscos pessoais, eles também temem que pessoas próximas, como familiares e amigos, sejam infectadas, inclusive por eles que mantêm contato direto como os pacientes doentes, por isso, se sentem estigmatizados ou insuficientes diante da situação do surto do vírus e da alta mortalidade, gerando nestes inúmeros problemas como ansiedade, estresse e depressão que podem trazer a eles, graves consequências a longo prazo.

\subsection{Fatores desencadeadores dos problemas de saúde mental durante a pandemia}

No Brasil, diante da decorrência da pandemia de COVID-19, foi decretado pelo Governo Federal, por meio da Portaria $n^{\circ} 340$, de 30 de março de 2020, recomendações sobre medidas para o enfrentamento da emergência em Saúde Pública de importância Nacional decorrente de infecção humana pela COVID-19, no âmbito das Comunidades Terapêuticas. Este documento também cita as medidas de isolamento social, revelando a necessidade dos indivíduos com suspeita do vírus e sintomáticos permanecerem em isolamento, como meio de diminuir a progressão e disseminação do vírus, resultando em controle, e menores taxas de morbidade e mortalidade (Diário Oficial da União do Brasil [DOU], 2020).

Contudo Santana et al. (2020) constataram que o isolamento social na pandemia do SARS-CoV-2 levou as pessoas a serem acometidas por mudanças psicológicas, como ansiedade, depressão e estresse, devido ao ser humano ser um ser social e por isso, dependem de interação, comunicação, interação interpessoal, e quando mantidas em isolamento, alimentam sentimentos de tédio, solidão e tristeza e, dos sentimentos experienciados, a ansiedade é o mais proeminente. Portanto, infere-se que a qualidade de vida das pessoas isoladas está muito ligada ao equilíbrio de sua saúde mental. Dentre os principais estressores durante a pandemia pela COVID-19 destacam-se o medo da infecção, o isolamento físico, a inadequação das informações, a estigmatização, a discriminação, as barreiras para vivenciar o luto daqueles que estão morrendo, o desespero em não poder se despedir daqueles que morreram, além das perdas financeiras (Brooks et al., 2020) 
Research, Society and Development, v. 10, n. 6, e50010616286, 2021

(CC BY 4.0) | ISSN 2525-3409 | DOI: http://dx.doi.org/10.33448/rsd-v10i6.16286

Por esta razão, Pfefferbaum e North (2020) reforçaram em seus estudos, a importância de apontar os fatores de suscetibilidade ao adoecimento mental durante a pandemia, que são principalmente a infecção pela doença ou a convivência com pessoa (s) infectada (s), portador de doença mental prévia, velhice, vulnerabilidade social, atuação na linha de frente (equipe de enfermagem e demais profissionais de saúde). Nesse sentido, acredita-se que outros aspectos identificados como estressores na pandemia de COVID-19 são a disseminação de falsas informações sem base científica, as notícias chocantes e delicadas, além da quantidade de tempo que as pessoas passam vendo notícias sobre a pandemia e suas consequências. Nesse sentido, Lima et al. (2020) relataram que a pandemia do SARS-CoV-2 trouxe impactos psicológicos e emocionais para as pessoas, podendo ser evidenciados pelo grande medo de contrair a doença, de morrer caso seja infectado, de ficar desempregado, desamparado ou de ser estigmatizado, além da incerteza quanto ao futuro tanto econômico, quanto educacional.

\subsection{Estratégias para mitigar os efeitos à saúde mental}

É de suma importância a implementação de estratégias e ou intervenções para que a população tenha acesso às medidas de apoio emocional diante deste momento pandêmico, seja presencial ou online. E em consonância, o Ministério da Saúde (2017) ressalva que no Brasil, é fornecida uma plataforma online, mas como algumas sociedades carecem de conhecimento ou de internet, nem todos se beneficiam dessa estratégia. Portanto, é imprescindível que o Sistema Único de Saúde (SUS), preste aos setores de saúde desprovidos dessa modalidade de atendimento, profissionais especializados em cuidados de saúde mental para atender seus beneficiários (BRASIL, 2017). Diante disso, três fatores principais devem ser considerados ao desenvolver estratégias em saúde mental, como equipes multidisciplinares que incluam médicos especialistas em psiquiatria, psicólogos, enfermeiros, farmacêuticos e outras especialidades em saúde; comunicação clara envolvendo atualizações regulares e precisas no surto de COVID-19 e estabelecimento de serviços de consultoria psicológica via telesaúde (Ortiz et al., 2020).

Assim, Nabuco, Oliveira e Afonso (2020) afirmam que os profissionais que fornecem o primeiro estágio de atendimento devem garantir os cuidados aos pacientes com infecção pelo SARS-CoV-2, como também os aspectos psicossociais relacionados. Portanto, compreender o processo psicológico é essencial para o entendimento que a saúde mental das pessoas vai muito além de estarem infectadas com o vírus, ou apenas de sobrevivência ou morte. Por isso, torna-se fundamental que os profissionais de saúde superem essa dicotomia, pois é indispensável para um melhor fornecimento do cuidado integral. Neste sentido Moreira et al., (2020) relatam em seus estudos que diante deste cenário, torna-se urgente a necessidade de promoção de ações qualificadas nos serviços de saúde, especialmente na área da enfermagem, pois estes desempenham um papel importante na categoria dos profissionais de saúde, como por exemplo, proporcionando intervenções estratégicas que enfoquem o enfrentamento das questões mentais.

Portanto, Araújo e Machado (2020) concluem que criar estratégias para garantir que os pacientes tenham acesso aos medicamentos e aos serviços de aconselhamento durante uma pandemia é essencial para prevenir a recorrência ou o agravamento de transtornos. O problema do uso de medicamentos prescritos pode ser resolvido pela decisão de estender o tempo dessa prescrição. A psicoterapia pode ser obtida através de métodos de consulta remota/online. Estas não são totalmente regulamentadas de forma adequada e muitas vezes sofrem oposição de associações profissionais. Porém acredita-se que essas estratégias devem ser amplamente aceitas e totalmente apoiadas pelo governo profissional da saúde.

Em consonância ao que se relatou sobre os fatores de risco ao adoecimento mental, o Ministério da Saúde adverte que a retomada de atividades contínuas, a interação social, a necessidade de disseminar ainda mais as medidas e práticas de promoção da SM são recomendadas pela OMS, assim como da importância em manter o sono regular e também os serviços online para cuidar de pacientes que precisam desses cuidados emocionais e espirituais são estratégias que promovem a SM da população, 
Research, Society and Development, v. 10, n. 6, e50010616286, 2021

(CC BY 4.0) | ISSN 2525-3409 | DOI: http://dx.doi.org/10.33448/rsd-v10i6.16286

uma vez que as limitações e o confinamento, o medo da doença, a perda de entes queridos, a incerteza frente ao futuro, o desemprego e a redução de renda são todos efeitos colaterais da pandemia e têm sido causa de doença mental no Brasil, assim como no mundo todo (BRASIL, 2020b). Moreira, Sousa e Nobrega (2020) corroboram e apontam que as evidências de intervenções de saúde mental para diferentes populações no contexto da pandemia, são nomeadamente, monitoramento remoto, jogos virtuais, intervenções de apoio social e técnicas de relaxamento muscular. A duração de tais intervenções varia e são caracterizadas por tratamentos não medicamentosos e de baixo custo, e precisa ser incentivada e incorporada aos programas de saúde mental.

Em detrimento disso, Nabuco, Oliveira e Afonso (2020) sugerem que dentre as orientações que ajudam a diminuir os impactos psicológicos na população durante o isolamento da pandemia estão o limite de exposição às notícias sobre o SARSCoV-2, que geram sintomas de ansiedade, medo em excesso e estresse; a busca de notícias por fontes de informações confiáveis e oficiais, evitando as "fake news", e tempo excessivo vendo noticiário; a manutenção de uma rotina, horário do sono e de refeições, incluindo exercícios físicos e lazer adequados ao isolamento; a garantia de interação com a família e amigos, mesmo de longe, seja por telefone, mídia social ou remotamente. Sendo assim, se faz imprescindível a ampliação da oferta de tecnologias que estabeleçam intervenções positivas de promoção do bem-estar psicossocial focadas no enfrentamento da traumatização secundária (Moreira, Sousa \& Nobrega, 2020).

Outro fator preventivo essencial e protetor para a manutenção do equilíbrio mental dos indivíduos em tempos de pandemia é a prática de atividade física regular, no qual pode auxiliar no controle da ansiedade e na regularização do sono Outro fator importante é a compreensão positiva acerca das medidas prevenção e contenção à proliferação da COVID-19, o que leva a um efeito positivo nas respostas psicológicas (Wang et al., 2020). Portanto, de acordo com Moreira, Sousa e Nobrega (2020), embora a curva do novo índice de infecção pelo novo Coronavírus (SARS-CoV-2) mostre uma tendência decrescente em escala global, as consequências relacionadas à saúde mental persistem e com efeitos nocivos a longo prazo. Por isso, uma estratégia individual e comunitária se faz urgente e necessária, assim como ações para minimizar a ocorrência de deterioração, problemas emocionais e psicológicos na população e em equipes de saúde, uma vez que esses problemas não podem ser ignorados.

Complementando os achados sobre o tema, Araújo \& Machado (2020), relatam em seus estudos, que ao longo do tempo, a pandemia do SARS-CoV-2 afetará a vida da maioria das pessoas de alguma forma. Por isso, acredita-se que a inclusão dos cuidados em saúde mental na agenda nacional de saúde pública para combater esta pandemia reduzirá os efeitos psicológicos onerosos e de longo prazo do tratamento dessas consequências. Contudo, Schmidt et al. (2020) ressaltam que este agravo que estamos vivenciando há mais de um ano, é considerada a maior emergência de saúde pública enfrentada pela comunidade internacional em décadas. E as contribuições de todos os profissionais, assim como da psicologia são necessárias nas intervenções psicológicas fornecidas neste momento pandêmico para minimizar os efeitos negativos e promover a saúde mental, bem como quando for necessário reajustar e lidar com perdas e mudanças posteriores. Nesse sentido, pesquisas adicionais sobre este tópico são essenciais e devem considerar as diferentes populações afetadas, sendo recomendado lidar com as consequências na saúde mental diante da pandemia e assim como o planejamento e execução de intervenções psicológicas em resposta às necessidades de toda população mundial, no decorrer do surto pandêmico.

\section{Conclusão}

No presente estudo, foi possível substanciar conhecimentos sobre os impactos na saúde mental e possíveis intervenções psicológicas utilizadas para a melhoria destas repercussões diante da pandemia do novo coronavírus. As medidas tomadas para a contenção do SARS-CoV-2 mostraram-se demasiadamente problemáticas quando analisadas as consequências 
Research, Society and Development, v. 10, n. 6, e50010616286, 2021

(CC BY 4.0) | ISSN 2525-3409 | DOI: http://dx.doi.org/10.33448/rsd-v10i6.16286

na saúde mental dos indivíduos, apresentando com maior frequência quadros de ansiedade, depressão, estresse e transtornos do estresse pós-traumático. Diante disso, intervenções psicológicas durante a pandemia são de suma importância para minimizar os impactos negativos e promover saúde mental, da mesma forma em momentos posteriores, quando as pessoas precisarão se readaptar a novas situações e lidar com perdas e transformações em todos os âmbitos.

Portanto, deve-se estimular pesquisas adicionais sobre a temática, bem como realizar levantamentos sobre esses impactos na saúde mental durante e após pandemia, traz consigo um importante peso nas intervenções psicológicas. São necessárias ações estratégicas individuais e de alcance comunitário para melhor atender as necessidades dos diferentes grupos que necessitam de ajuda profissional, minimizando os efeitos emocionais e agravos psicológicos sem negligenciar as equipes de saúde.

Este estudo é relevante para a comunidade científica, pois após a análise dos impactos psicológicos que mais acometem a população mundial, torna-se possível traçar estratégias para prevenção e enfrentamento desses impactos, uma vez que cuidar da saúde mental, é essencial para que o corpo tenha equilíbrio e mais resistência ao SARS-CoV-2. Assim, deve-se dar a devida importância para essa área da saúde que está sendo negligenciada e que necessita de investimento em pesquisas com o intuito de buscar soluções para um tratamento efetivo e assim implementar ações estratégicas, tanto individuais como comunitárias para minimizar os agravos psicológicos e transtornos emocionais na população e em profissionais de saúde, pois as consequências relacionadas a saúde mental são evidentes e podem gerar efeitos danosos a longo prazo.

\section{Referências}

Accorsi, D. X., et al. COVID-19 e o Sistema Nervoso Central. Revista Ulakes, v. 1, 2020. Disponível em: Accorsi, D. X., Santos, I.A. M., Accorsi, J. X., Bohac, S., \& Chin, C. M. (2020). COVID-19 e o Sistema Nervoso Central. Revista Ulakes, 1(1), 81-87.

Ahmed, M. Z., Ahmed, O., Aibao, Z., Hanbin, S., Siyu, L., \& Ahmad, A. (2020). Epidemic of COVID-19 in China and Associated Psychological Problems. Asian Journal of Psychiatry, 51(1), 1-7.

Araujo, L. F. S. C., \& Machado, D. B. (2020). Impact of COVID-19 on mental health in a Low and Middle-Income Country. Ciência \& Saúde Coletiva, $25(1), 2457-2460$.

Artal, F. J. C. (2020). Complicaciones neurológicas por coronavirus y COVID-19. Revista de Neurología, 70(9), $311-322$.

Asmundson, G. J. G, \& Taylor, S. (2020). Coronaphobia: Fear and the 2019-nCoV outbreak. Journal of anxiety disorders, 70(1), $102196-102197$.

Bagcchi, S. (2020). Stigma during the COVID-19 pandemic. The Lancet. Infectious Diseases, $20(7), 782$.

Barros, M. B. De A., Lima, M. G., Malta, D. C., Szwarcwald, C. L., Azevedo, R. C. S. De, Romero, D., Souza Júnior, P. R. B., Azevedo, L. O., Machado, I. E., \& Damacena, G. N. (2020). Relato de tristeza/depressão, nervosismo/ansiedade e problemas de sono na população adulta brasileira durante a pandemia de COVID-19. Epidemiologia e Serviços de Saúde, 29(4), 1-11.

Brasil, Ministério da Saúde. Secretaria de Vigilância em Saúde. (2020a). Guia de Vigilância Epidemiológica: Emergência de Saúde Pública de Importância Nacional pela Doença pelo Coronavírus 2019. Vigilância de Síndromes Respiratórias Agudas COVID-19. Brasília/DF, 2020. Autor. Recuperado de https://portalarquivos.saude.gov.br/images/af_gvs_coronavirus_6ago20_ajustes-finais-2.pdf. Acesso em 30 set.2020.

Brasil. Ministério da Saúde. (2020b). Dispõe sobre a transferência de recursos financeiros de custeio para a aquisição de medicamentos do Componente Básico da Assistência Farmacêutica utilizados no âmbito da saúde mental em virtude dos impactos sociais ocasionados pela pandemia da COVID-19. Edição: 182 /Seção: 1; Página: 99 Brasília: Autor. Recuperado de https://www.in.gov.br/en/web/dou/-/portaria-n-2.516-de-21-de-setembro-de-2020-278695720.

Brooks, S. K., Webster, R. K., Smith, L. E., Woodland, L., Wessely, S., Greenberg, N., \& Rubin, G. J. (2020). The psychological impact of quarantine and how to reduce it: rapid review of the evidence. The Lancet, 395(10227), 912-920.

Castro, P. J. S., Estivill-Torrús, G., Cabezudo-García, P., Antonio Reyes-Bueno, J., Petersen, N. C., Aguilar-Castillo, M. J., \& ... de Fonseca, F. R. (2020). Influência de la infección SARS-CoV-2 sobre enfermedades neurodegenerativas y neuropsiquiátricas: ¿una pandemia demorada?. Neurología, 35 , n. 4 , p. $245-251$.

Diário Oficial da União do Brasil. (2020). Portaria No340, de 30 de março de 2020. Brasilia: Autor. Recuperado de https://www.in.gov.br/en/web/dou//portaria-n-340-de-30-de-marco-de-2020-250405535. 
Research, Society and Development, v. 10, n. 6, e50010616286, 2021

(CC BY 4.0) | ISSN 2525-3409 | DOI: http://dx.doi.org/10.33448/rsd-v10i6.16286

Duan, L., \& Zhu, G. (2020). Psychological interventions for people affected by the COVID-19 epidemic. The Lancet Psychiatry, 7(4), 300-302. Fernandes, H. M. L. G., Jesus, M. V. N., Silva, D., \& Guirardello, E. B. (2020). Lean Healthcare in the institutional, professional, and patient perspective: an integrative review. Revista Gaúcha de Enfermagem, 41(1), 1-12.

Fundação Oswaldo Cruz. (2020). Saúde mental e atenção psicossocial na pandemia COVID-19: recomendações gerais. Brasília/DF. Autor. Recuperado de https://www.fiocruzbrasilia.fiocruz.br/wp-content/uploads/2020/04/Sa\%C3\%BAde-Mental-e-Aten\%C3\%A7\%C3\%A3o-Psicossocial-na-Pandemia-Covid-19recomenda\%C3\%A7\%C3\%B5es-gerais.pdf.

Gao, J., Zheng, P., Jia, Y., Chen, H., Mao, Y., Chen, S., Wang, Y., Fu, H., \& Dai, J. (2020). Mental health problems and social media exposure during COVID-19 outbreak. Plos One, 15(4),1-10.

Holmes, E. A., O’Connor, R. C., Perry, V. H., Tracey, I., Wessely, S., Arseneault, L., Ballard, C., Christensen, H., Silver, R. C., \& Everall, I. (2020). Multidisciplinary research priorities for the COVID-19 pandemic: a call for action for mental health science. The Lancet Psychiatry, 7(6), 547-560.

Lai, J., Ma, S., Wang, Y., Cai, Z., Hu, J., Wei, N., Wu, J., Du, H., Chen, T., \& Li, R. (2020). Factors Associated With Mental Health Outcomes Among Health Care Workers Exposed to Coronavirus Disease 2019. Jama Network Open, 3(3), 1-12.

Lima, S. O, Silva, M. A., Santos, M. L. D., Moura, A. M. M., Sales, L. G. D., Menezes, L. H. S., Nascimento, G. H. B., Oliveira, C. C. C., Reis, F. P., \& Jesus, C. V. F. (2020). Impactos no comportamento e na saúde mental de grupos vulneráveis em época de enfrentamento da infecção COVID-19: revisão narrativa. Revista Eletrônica Acervo Saúde, 46(1), 4006.

Liu, S., Yang, L., Zhang, C., Xiang, Y.-T., Liu, Z., Hu, S., \& Zhang, B. (2020). Online mental health services in China during the COVID-19 outbreak. The Lancet Psychiatry, 7(4), 17-18.

Mendes, K. D. S., Silveira, R. C. C. P., \& Galvão, C. M. (2008). Revisão integrativa: método de pesquisa para a incorporação de evidências na saúde e na enfermagem. Texto \& contexto enfermagem, 17(4), 758-764.

Minayo, M. C. S. (2017). Amostragem e saturação em pesquisa qualitativa: consensos e controvérsias. Revista pesquisa qualitativa, 5(7), 1-12 Moreira, W. C., Sousa, A. R., \& Nobrega, M. P. S. S. (2020). Adoecimento mental na população geral e em profissionais de saúde durante a covid-19: scoping review. Texto \& Contexto-Enfermagem, (29).

Moreira, W. C., Sousa, K. H. J. F., Sousa, A. R., Santana, T. S., Zeitoune, R. C. G., \& Nóbrega, M. P. S. S. (2020). Intervenções em saúde mental em tempos de COVID-19: scoping review. Health Sciences, $1-21$.

Nabuco, G., Oliveira, M. H. P. P., \& Afonso, M. P. D. (2020). O impacto da pandemia pela COVID-19 na saúde mental. Revista Brasileira de Medicina de Família e Comunidade, 15(42), 1-11.

Oliveira, M. L. M. C, Ayres, P., Reis, G. G., Toledo, A. L. M., \& Silva, S. C. (2020). Lêvitude emocional e as estratégias da Teoria CognitivoComportamental para o enfrentamento do COVID-19. Revista Enfermagem e Saúde Coletiva-REVESC, 5(1), 1-11.

Organização Mundial da Saúde. (2020). Saúde mental e considerações psicossociais durante o surto de COVID-19, 18 de março de 2020. Brasília/DF. Autor. Recuperado de https://apps.who.int/iris/bitstream/handle/10665/331490/WHO-2019-nCoV-MentalHealth-2020.1-eng.pdf.

Ortiz, J. R., Quintero, D. C., Córdoba, C. L., Ceballos, F. Y., \& Córdoba, F. E. (2020). Mental health consequences of the COVID-19 pandemic associated with social isolation. Colombian Journal Of Anesthesiology, 48(4), 1-7.

Pereira, M. D., Oliveira, L. C., Costa, C. F. T., Bezerra, C. M. O., Pereira, M. D., Santos, C. K. A., \& Dantas, E. H. M. (2020). The COVID-19 pandemic, social isolation, consequences on mental health and coping strategies: an integrative review. Research, Society and Development, 9(7), 135 .

Pfefferbaum, B.; North, C. S. (2020). Mental health and the Covid-19 pandemic. New England Journal of medicine, 383(6), 510-512.

Santana, V. V. R. S., Nascimento, R. Z., Lima, A. A., \& Nunes, I. C. M. (2020). Alterações psicológicas durante o isolamento social na pandemia de covid-19: revisão integrativa. Revista Família, Ciclos de Vida e Saúde no Contexto Social, 1(8), 754-759.

Schmidt, B., Crepaldi, M. A., Bolze, S. D. A., Silva, L. N., \& Demenech, L. M.(2020). Saúde mental e intervenções psicológicas diante da pandemia do novo coronavírus (COVID-19). Estudos de Psicologia (Campinas), (37), 1-13.

Silva, B., Jorge, A., \& Luzeiro, I. (2020). Manifestações Neurológicas em Doentes com Infeção por SARS-CoV-2. Sinapse, 20(2), 9-16.

Talevi, D., Socci, V., Carai, M., Carnaghi, G., Faleri, S., Trebbi, E., Bernardo, A., Capelli, F., \& Pacitti, F. (2020). Mental health outcomes of the CoViD-19 pandemic. Rivista di Psichiatria, 55(3), 137-144.

Vasconcelos, C. S. S., Feitosa, I. O., Medrado, P. L. R., Brito, A. P. B. (2020). O novo coronavírus e os impactos psicológicos da quarentena. Desafios - Revista Interdisciplinar da Universidade Federal do Tocantins, 7(3), 75-80. 
Research, Society and Development, v. 10, n. 6, e50010616286, 2021

(CC BY 4.0) | ISSN 2525-3409 | DOI: http://dx.doi.org/10.33448/rsd-v10i6.16286

Wang, C., Pan, R., Wan, X., Tan, Y., Xu, L., Ho, C. S., \& Ho, R. C. (2020). Immediate psychological responses and associated factors during the initial stage of the 2019 coronavirus disease (COVID-19) epidemic among the general population in china. International Journal of Environmental Research and Public Health, 17(5), 1729.

Xu, Z., Shi, L., Wang, Y., Zhang, J., Huang, L., Zhang, C., LIU, S., ZHAO, P., LIU, H., \& ZHU, L. (2020). Pathological findings of COVID-19 associated with acute respiratory distress syndrome. The Lancet Respiratory Medicine, 8(4), 420-422.

Zhang, C., Yang, L., Liu, S., Ma, S., Wang, Y., Cai, Z., ... Zhang, B. (2020a). Survey of insomnia and related social psychological factors among medical staff involved in the 2019 novel coronavirus disease outbreak. Frontiers in Psychiatry, 11(306), 1-9. 